\title{
Revision rate of THA in patients younger than 40 years depends on primary diagnosis - a retrospective analysis with a minimum follow-up of 10 years
}

\author{
Stefan Rahm ${ }^{1} \cdot$ Armando Hoch $^{1}$ [D - Timo Tondelli ${ }^{1}$ Johannes Fuchs ${ }^{1} \cdot$ Patrick O. Zingg ${ }^{1}$
}

Received: 11 November 2020 / Accepted: 15 January 2021 / Published online: 25 January 2021

(c) The Author(s) 2021

\begin{abstract}
Background Treating osteoarthritis in elderly patients with THA is very successful. However, surgeons hesitate to recommend THA in younger patients. The spectrum of etiologies for end stage hip disease in the younger population is diverse and therefore different courses may be assumed. Our objective was to evaluate THA revision rate within a minimum follow-up period of 10 years in young patients and to analyze the difference between different primary diagnoses.

Methods We included 144 consecutive hips in 127 patients younger than 40 years, who received a primary THA from 01/1996 to 12/2007. Operative reports, clinical and radiographic documentation were reviewed to determine primary diagnosis, prior hip surgery, component specifications and revision surgery. 111 hips in 97 patients were available for outcome analysis with a minimum follow-up of 10 years.

Results The mean age was 33 years (range 15-40 years) at the time of the index THA, 68 patients were female and 59 were male. Ten years revision rate on the prosthetic components was $13 \%$. The most common primary diagnosis was DDH. DDH was associated with a risk of $17 \%$ for requiring a reoperation on the prosthetic components because of mechanical fatigue and therefore, significantly higher than for any other primary diagnosis $(p=0.005)$.

Conclusion THA in young patients is associated with a high revision rate of $13 \%$ in 10 years. $17 \%$ of patients with DDH required revision surgery for mechanical fatigue within 10 years, which was significantly higher than for any other primary diagnosis (1.2\%, OR 16.8).
\end{abstract}

Keywords Total hip arthroplasty $\cdot$ Primary diagnosis $\cdot$ Prior surgery $\cdot$ Complication $\cdot$ Revision surgery $\cdot$ Developmental dysplasia of the hip

\section{Introduction}

Total hip arthroplasty (THA) revision rates are strongly correlated with the patients' activity and therefore known to be higher in younger patients [1-4]. Furthermore, the type of failure in younger patients differs from an older population and is often of a mechanical cause (e.g., aseptic loosening) [5]. However, implant design as well as surgical approaches and techniques have changed over time and revision rates have decreased [6-8]. While THA may deliver

Stefan Rahm, Armando Hoch equally contributed.

Armando Hoch

armando.hoch@balgrist.ch

1 Department of Orthopaedics, Balgrist University Hospital, Forchstrasse 340, 8008 Zurich, Switzerland good long-term results even in young patients [9-21], there are also reports about unpredictability of short- to long-term outcome [22-29]. Many studies were designed to identify the best technique or implant design for younger patients, or they focused on a subgroup of patients with a specific primary diagnosis [9-11, 13, 14, 17-21, 30-32]. So far, there is knowledge about the outcome in a mid- to long-term followup in patients with juvenile idiopathic arthritis as one of the historically most accepted indications for THA in young patients [30-32]. Recently, more attention is given to the outcome of THA for different non-inflammatory indications in younger patients. Mostly, the influence of prior surgeries or technical aspects on the revision rate is investigated [5, $20,21,33]$. However, the influence of the primary diagnosis on the risk for revision surgery is still unclear. Our objective was to evaluate THA revision rate within a minimum 
follow-up period of 10 years in young patients and to analyze the difference between different primary diagnoses.

\section{Methods}

\section{Study population}

After approval of the study by the responsible ethical review board (KEK Zurich BASEC Nr. 2017-01,616), a retrospective data analysis was conducted. From our institute's archive, data of all patients under 40 years who received a primary THA in the period from 01/1996 to $12 / 2007$ were retrieved. 127 consecutive patients with 144 THA were identified and invited to participate in the study including a clinical and radiographic follow-up assessment. Of these 127 patients, 30 patients (33 THA) were lost to follow-up within the minimum follow-up period of 10 years: 3 could not be tracked through the local authority, 6 refused to participate, another 4 were lost because they developed a disabling medical condition and were not able to participate in the study, 12 emigrated and 5 deceased (Fig. 1). Finally, 97 patients (111 hips) were evaluated for clinical and radiographic outcome after a minimum follow-up of 10 years. Nevertheless, the 30 patients who were lost, were included in the implant survival analysis according to Kaplan-Meier. At the last follow-up 99 hips (89\%) were assessed clinically and radiographically, 1 hip (1\%) was assessed only clinically and 11 hips (10\%) were assessed through a telephone enquiry.

\section{Clinical assessment}

Our institute's digital clinical information system was used to search for detailed patient history. Regarding the patients' history, the primary diagnosis and prior surgeries before implantation of the index THA were assessed. The surgical report was reviewed to determine the surgical approach, the

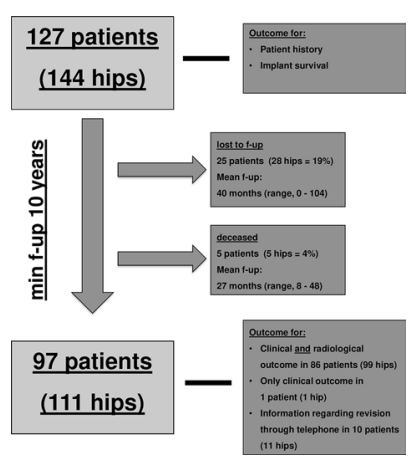

Fig. 1 This figure gives an overview over the patient enrollment process with details to the patients lost to follow-up and the outcome parameters method of fixation of cup and stem and the type of prosthetic components. We analyzed all complications after index THA surgery and the subsequent reoperations, where we differentiated between re-operations with and without revision of the prosthetic components. Major revision surgery was defined as re-operation on the prosthetic components, where we differentiated between re-operations on fixed (cup and stem) and on mobile (head and liner) parts. As patientreported outcome measures (PROMS) the Western Ontario and McMaster Universities Osteoarthritis Index (WOMAC) [34] and the Harris Hip Score [35] were assessed at the last follow-up after a minimum of 10 years.

\section{Radiographic assessment}

AP pelvis and cross-table lateral view radiographs were available for analysis. Osteolysis around the cup was assessed according to the DeLee and Charnley classification [36], whereas osteolysis around the stem was assessed according to the Gruen classification [37]. The amount of stress-shielding was assessed with the semiquantitative technique developed by Engh [38]. To assess loosening of the stem we quantified a possible subsidence which was determined relevant when at least $2 \mathrm{~mm}$ subsidence was present compared to the postoperative radiograph after the index procedure $[39,40]$. The presence of spot welds was used as an indicator for stability [41]. Furthermore, heterotopic ossification was quantified according to Brooker [42]. Severe ossification was determined Brooker grade 3 or 4 . Eccentric wear was assessed in a qualitative manner and defined as positive when the center of rotation of the head was cranial to the center of rotation of the cup.

\section{Statistical analysis}

Implant survival was calculated using the Kaplan-Meierestimator. Nonparametric methods were applied due to nonnormal distributed data. The effect on outcomes of categorical and continuous variables was analyzed by Fisher's exact and Kruskal-Wallis test, respectively. In case of statistically significant effects, a post-hoc Wilcoxon rank-sum test was conducted. If not stated otherwise, median and range are reported. The significance level was set at 0.05 . Statistical analyses were computed using Stata/IC 15.1 (StataCorp LP, College Station, TX, USA).

\section{Results}

The mean age of all patients was 33 years (range 15-40 years) at the time of the index THA. Sixty-eight patients were female and 59 were male. The distribution of primary diagnosis, perioperative data and component 
specifications for each hip with a minimum follow-up of 10 years are summarized in Table 1.

\section{Implant survival}

The overall implant survival (lack of revision for any reason) was $94 \%$ at 2 years ( $n=117,95 \%$ CI $0.88 ; 0.97), 90 \%$ at 5 years $(n=104,95 \% \mathrm{CI} 0.83 ; 0.94), 87 \%$ at 10 years $(n=96,95 \%$ CI $0.80 ; 0.92)$ and $83 \%$ at 15 years $(n=45$, CI $0.74 ; 0.89$ ) (Fig. 2). The 33 hips that were lost to a full 10-year follow-up were tracked for a mean time of 23 months (range 0-104 months). Of the 33 hips that were lost to follow-up before 10 years, two needed a revision on the prosthetic components. Both had a revision of the stem because of a periprosthetic fracture 1 and 18 months after index THA, respectively. In addition, 4 hips needed a minor revision without reoperation on the prosthetic components.

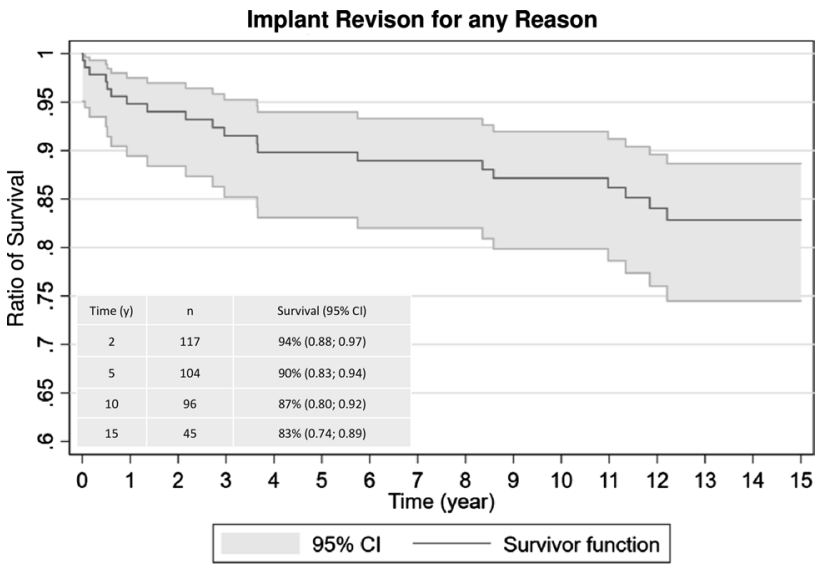

Fig. 2 This figure shows the survival rate for the prosthesis within a 15 -year follow-up period

Table 1 Patient specification

\begin{tabular}{|c|c|c|}
\hline \multicolumn{3}{|l|}{ Primary diagnosis } \\
\hline Developmental dysplasia of the hip (DDH) & & $29(25 \%)$ \\
\hline Osteonecrosis of the femoral head $(\mathrm{ON})$ & & $27(24 \%)$ \\
\hline Post-traumatic osteoarthritis & & $21(19 \%)$ \\
\hline Impingement related osteoarthritis (FAI) & & $8(7 \%)$ \\
\hline Ankylosing spondylitis (AS) & & $5(5 \%)$ \\
\hline Slipped capital femoral epiphysiolisis (SCFE) & & $5(5 \%)$ \\
\hline Legg-calve-perthes-disease (LCPD) & & $5(5 \%)$ \\
\hline Rheumatoid arthritis (RA) & & $4(4 \%)$ \\
\hline Secondary osteoarthritis after septic arthritis & & $3(3 \%)$ \\
\hline Epiphyseal dysplasia & & $2(2 \%)$ \\
\hline Hemophilia & & $1(1 \%)$ \\
\hline Mukolipidosis & & $1(1 \%)$ \\
\hline \multicolumn{3}{|l|}{ Perioperative Data } \\
\hline Prior hip surgery & & $54(49 \%)$ \\
\hline \multirow[t]{4}{*}{ Approach } & Anterior & $27(24 \%)$ \\
\hline & Trochanter osteotomy & $36(32 \%)$ \\
\hline & Transgluteal & $36(32 \%)$ \\
\hline & Posterior & $12(11 \%)$ \\
\hline \multicolumn{3}{|l|}{ Component specifications } \\
\hline \multirow[t]{2}{*}{ Femoral component } & Cemented & $73(66 \%)$ \\
\hline & Cementless & $38(34 \%)$ \\
\hline \multirow[t]{4}{*}{ Femoral head size } & 22 & $7(6 \%)$ \\
\hline & 28 & $100(90 \%)$ \\
\hline & 32 & $3(3 \%)$ \\
\hline & 36 & $1(1 \%)$ \\
\hline \multirow[t]{2}{*}{ Acetabular component } & Pressfit & $67(60 \%)$ \\
\hline & Reinforcement ring with cemented inlay & $44(40 \%)$ \\
\hline \multirow[t]{4}{*}{ Bearing } & Metal on conventional polyethylene & $12(11 \%)$ \\
\hline & Metal on highly cross-linked polyethylene & $79(71 \%)$ \\
\hline & Metal on metal & $12(11 \%)$ \\
\hline & Ceramic on ceramic & $1(1 \%)$ \\
\hline
\end{tabular}


These were fixation of a secondarily displaced greater trochanter in one case and hardware removal in 3 cases.

After the follow-up period of 10 years, the re-operation rate on the prosthetic components was 13\% (16 hips). In 8\% (10 hips) a revision of the stem, and in 10\% (12 hips) a revision of the cup was necessary. After the follow-up period of 15 years the revision rate was 17\% (20 hips). In 10\% (12 hips) a revision of the stem, and in $12 \%$ a revision of the cup was necessary.

\section{Complications}

In the 111 hips with a minimum of 10 years follow-up, complications occurred in 46 hips (42\%). Of these 46 hips, 4 were treated conservatively and 42 underwent subsequent surgery, whereas 19 underwent minor re-operations without and 23 major re-operations with revision of the prosthetic components. The details are summarized in Table 2. In 8 hips (38\%) the cup was revised, in 6 hips (29\%) the stem was revised and in 7 hips (33\%) both cup and stem were revised.

Cases of aseptic loosening of the cup, late aseptic loosening of the stem and eccentric wear were merged in order to group the hips showing sequela of mechanical fatigue. No cases of early loosening of the stem were identified. This category of mechanical fatigue related failures was one of the two most frequent reasons for revision on the prosthetic components in $29 \%(n=6)$ of all revisions. The implant survival in this group (revision for mechanical fatigue) reached $99 \%$ at 2 years $(n=111,95 \%$ CI $0.94 ; 1.00), 98 \%$ at 5 years $(n=110,95 \%$ CI $0.93 ; 1.00), 97 \%$ at 10 years $(n=107,95 \%$ CI $0.92 ; 0.99)$ and $95 \%$ at 15 years $(n=52$, CI $0.88 ; 0.98)$. The other of the two most frequent reasons for revision on the prosthetic components were periprosthetic joint infection (PJI), which was responsible for $29 \%(n=6)$ of all revisions, where both cup and stem were revised. The third most frequent reason was revision of the cup because of irritation of the psoas tendon in cases of anterior uncoverage of the cup or increased tension of the iliotibial band due to non-anatomical reconstruction with increased lateral offset responsible for $24 \%(n=5)$ of the revisions (Table 2$)$.

\section{Subgroup analysis}

The primary diagnoses for THA in the patients that needed revision surgery and the type of performed revision surgery are summarized in Table 3. A timeline of the 21 hips with revision of the fixed parts of the prosthetic components is depicted in Fig. 3. Developmental dysplasia of the hips (DDH) as primary diagnosis was associated with a higher re-operation rate on the prosthetic components because of mechanical fatigue compared to the other primary diagnoses (DDH $17.2 \%$ vs. other $1.2 \% ; p=0.005$, OR $16.8,95 \%$ CI
Table 2 Complications

\begin{tabular}{|c|c|c|}
\hline \multicolumn{3}{|c|}{ Conservatively treated complications $(n=4)$} \\
\hline Fracture $^{\mathrm{a}}$ & & $1(25 \%)$ \\
\hline Temporary nerve palsy & & $1(25 \%)$ \\
\hline One-time dislocation & & $2(50 \%)$ \\
\hline \multicolumn{3}{|c|}{ Surgically treated complications $(n=42)$} \\
\hline Reason for minor reoperations & & 19 \\
\hline Hardware removal & & $11(58 \%)$ \\
\hline Internal fixation ${ }^{\mathrm{b}}$ & & $3(16 \%)$ \\
\hline Lengthening of psoas tendon & & $2(11 \%)$ \\
\hline Wound revision & & $1(5 \%)$ \\
\hline Excision of seroma & & $1(5 \%)$ \\
\hline Excision of heterotopic ossification & & $1(5 \%)$ \\
\hline Reason for major reoperations & & 23 \\
\hline Revision of fixed parts & & $21(91 \%)$ \\
\hline \multirow[t]{3}{*}{ Mechanical fatigue } & Aseptic loosening cup & 3 \\
\hline & Aseptic loosening stem & $2(29 \%)$ \\
\hline & Eccentric wear & 1 \\
\hline Periprosthetic joint infection & & $6(29 \%)$ \\
\hline Irritation of soft tissues & & $5(24 \%)$ \\
\hline Breakage of stem & & $2(10 \%)$ \\
\hline Periprosthetic fracture & & $2(10 \%)$ \\
\hline Revision of mobile parts & & $2(9 \%)$ \\
\hline Periprosthetic joint infection & & $2(100 \%)$ \\
\hline
\end{tabular}

${ }^{\mathrm{a}}$ Vancouver Type AGT, undislocated, ${ }^{\mathrm{b}}$ Vancouver Type $1 \times \mathrm{AGT}$, dislocated, $2 \times \mathrm{C}$ 


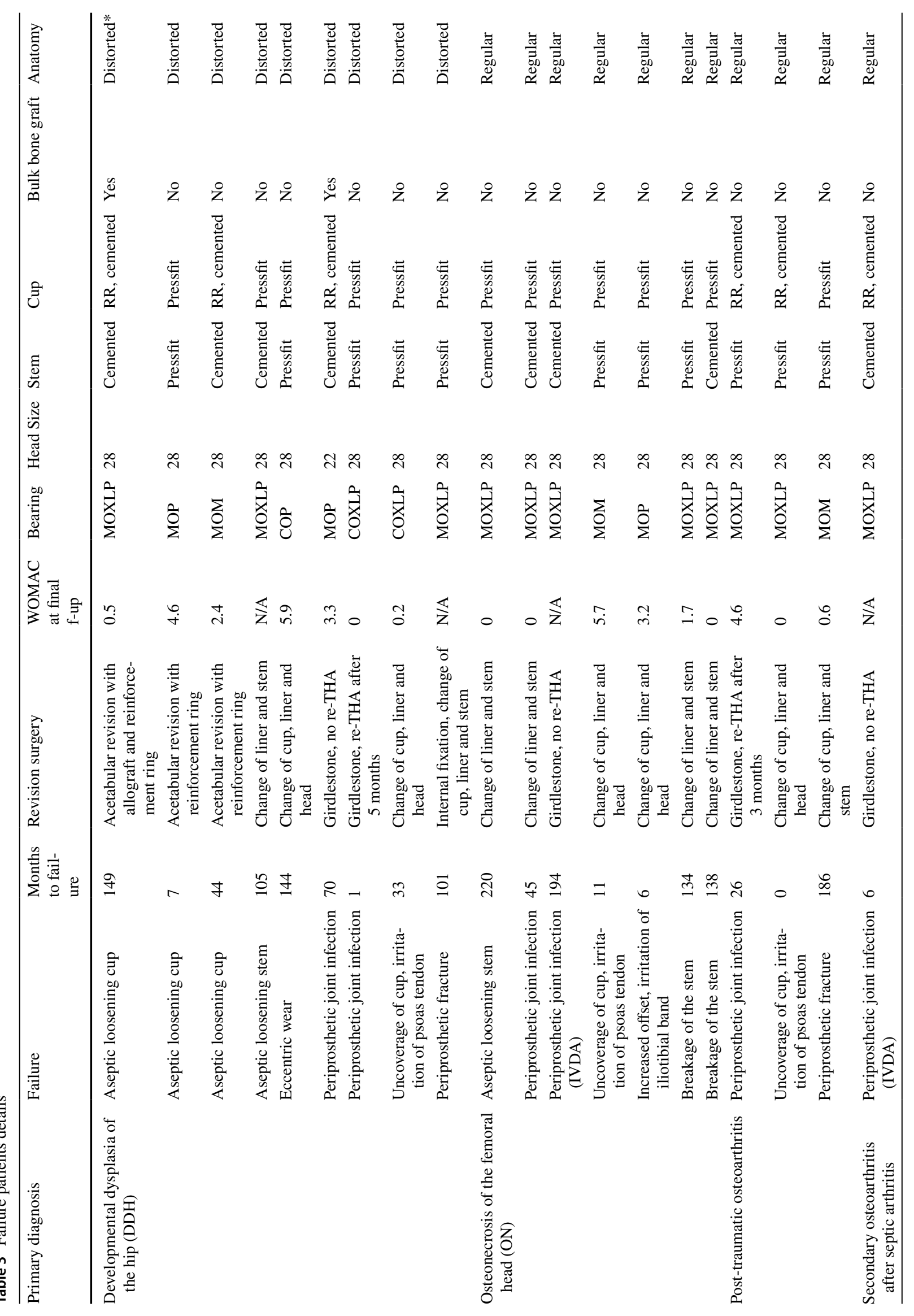


Table 4 Patients at risk for revision surgery

\begin{tabular}{lll}
\hline Eccentric wear & & $6(7 \%)$ \\
Relevant osteolysis & & $5(5 \%)$ \\
Cup & & 2 \\
Stem & & 3 \\
& Late & 1 \\
& Distal & 2 \\
\hline
\end{tabular}

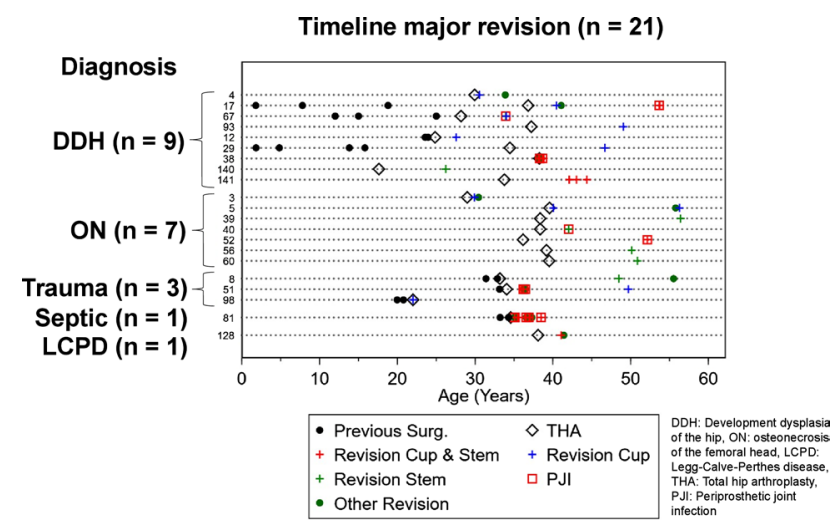

Fig. 3 This figure shows the hips, which underwent revisions surgery on the prosthetic components (major revision) with details on primary diagnosis, and the type of previous and revision surgeries

$2.45 ; \infty)$. An example case with aseptic loosening of the cup is depicted in Fig. 4. However, DDH was not associated with a higher risk for reoperation on the prosthetic components for any reason $(p=0.095)$. This was due to the fact that the other frequent reasons for reoperation on the prosthetic components (PJI, soft tissue irritation) were equally distributed between the different primary diagnoses.

The history of prior surgery was not associated with a higher risk for reoperation on the prosthetic components $(p=0.333)$. Furthermore, neither the usage of cement for fixation of the stem in primary THA $(p=0.073)$, the head size $(p=0.103)$, the technique of acetabular fixation $(p=0.325)$, nor the material property of the used liner $(p=0.476)$ was associated with a higher risk for re-operation on the prosthetic components.

\section{PROMS and radiographs at latest follow-up}

The median WOMAC at last follow-up was 0.8 points (range 0-5.9), and the HHS was 95 (range 36-100) points for the whole collective. These values were not significantly different from the corresponding values of $0.6(p=0.95)$ for the WOMAC and $91.5(p=0.55)$ for the HHS in patients that underwent a reoperation on the prosthetic components.

At the last follow-up radiograph, a subsidence of the stem was present in $3 \%$ of the hips. This subsidence occurred 
Fig. 4 This figure depicts an example case for a patient with $\mathrm{DDH}$, who underwent revision surgery on the prosthetic components due to mechanical fatigue

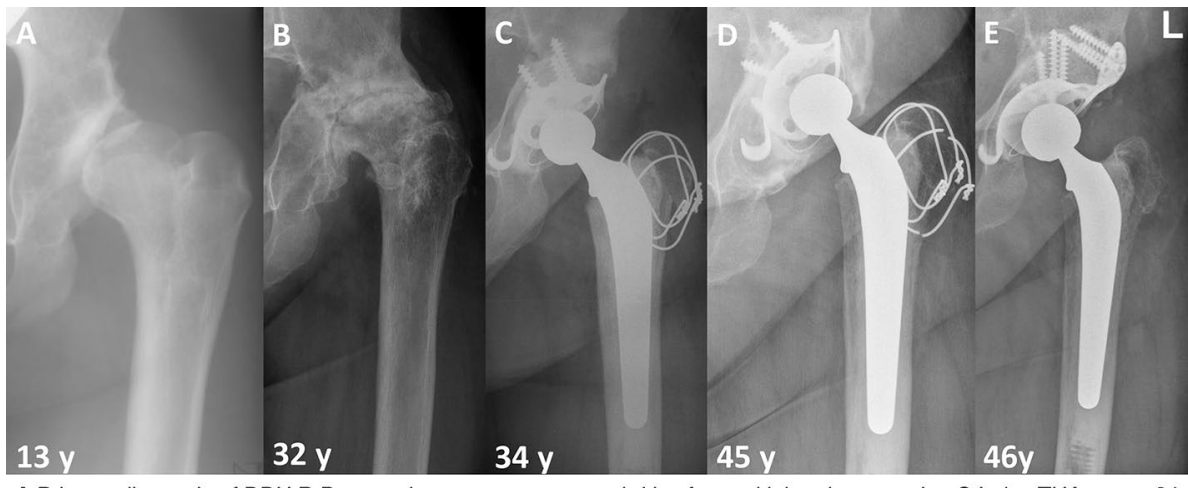

A Primary diagnosis of DDH B Progression to severe osteoarthritis after multiple prior surgeries $\mathbf{C}$ Index THA at age 34 D Aseptic loosening of the cup 12 years after index THA E Situation after revision of the cup (WOMAC Score of 0.5) within the first year after index THA in all cases and did not progress subsequently. Heterotopic ossifications were seen in $38 \%$ of the hips, relevant ossifications were seen in 5\% of the hips. Radiographic osteolysis around the stem was present in $20 \%$ of the hips, whereas relevant osteolysis in more than 3 of the Gruen zones was present in 3\% of the hips (Table 4). Osteolysis around the cup was seen in 5\% of the hips, whereas osteolysis of in more than 1 of the DeLee and Charnley zones was present in $2 \%$ of the hips. Eccentric wear was present in $7 \%$ of the hips, whereas it was significantly more often when a standard polyethylene acetabular liner was used $(p=0.026) .9$ hips ( $9 \%)$ are all either planned for a revision or the patients are seen on a regular basis in our outpatient clinic due to their radiographic risk profile (e.g., eccentric wear). These hips at risk for revision are listed in Table 4. Two of them showed 2 characteristics to put them at risk: one hip shows eccentric wear which led to late osteolysis around the stem. Another patient shows eccentric wear which led to osteolysis around the cup. The 2 osteolyses around the distal stem are seen in both hips of one patient with ankylosing spondylitis. If these hips were included in the survival analysis, the 10-year survival would be $79 \%$ ( $n=87,95 \%$ CI $0.70 ; 0.85)$. Nevertheless, these patients were not all symptomatic.

\section{Discussion}

In this study, we found a rather high rate of $13 \%$ of patients requiring a reoperation rate on the prosthetic components after a follow-up period of ten years. A further $9 \%$ of our collective are either currently planned to undergo or at a high risk of requiring revision surgery on the prosthetic components in the near future due to wear or osteolysis.

One of the two most frequent reasons for revision surgery on the prosthetic components was failure due to mechanical fatigue. Within this group, developmental dysplasia of the hip was by far the most frequent primary diagnosis and associated with a significantly higher re-operation rate on the prosthetic components $(p=0.005)$. For hips with DDH, the re-operation rate on the prosthetic components due to mechanical fatigue after ten years was $17 \%$ compared to $1.2 \%$ for hips with other primary diagnoses (OR 16.8). This presumably relates to the fact that these patients have a distorted bony anatomy. The prevalence of prior surgeries before index THA was high in this group. But interestingly, there was no significantly higher risk for a re-operation associated with prior surgery $(p=0.333)$. We believe a major reason for the higher risk for re-operation on the prosthetic components in patients with DDH was the fact that the surgery itself is technically demanding due to the distorted anatomy, such as a shallow acetabulum, a thin anterior wall, a narrow femoral canal and other conspicuous anatomical features requiring deviation from the usual surgical procedure [43]. Interestingly, older patients who underwent THA because of DDH had a similar outcome compared to those with primary OA [44]. This fact may be explained by the lower level of activity in older patients [1-4]. Nonetheless, our collective was young. One the one hand these patients might have had a more severe alteration of the bony anatomy making THA at young age necessary, on the other hand these patients are more active which puts them at higher risk for a revision. Hips with osteonecrosis of the femoral head and post-traumatic OA generally do not have significantly distorted anatomy. This might contribute to the lower risk of requiring a reoperation on the prosthetic components because of mechanical fatigue in these hips.

Overall patient-reported outcome measures reached 0.8 points for the WOMAC and 95 points for the HHS. Therefore, these results are comparable to the general collective of patients undergoing THA $[45,46]$. Even patients with DDH after revision surgery on the prosthetic components still showed good outcome measures at the latest follow-up.

In the current literature, successively more attention is paid to outcome measures of THA for different noninflammatory indications in younger patients. Mostly, the influence of prior surgeries or technical aspects on the outcome is investigated [5, 20, 21, 33]. Kargin et al. 
evaluated 44 hips in 35 patients younger than 30 years with a mean follow-up of 8 years [20]. Their focus was on the influence of prior hip surgery before index THA on the patient reported outcome and the complication rate. They stated that prior hip surgery did not lead to an inferior outcome. This is in line with the results from our investigation. Swarup et al. included 548 hips in 400 patients younger than 35 years with a mean follow-up of 14 years [21]. Like in our study, the revision free implant survival was $87 \%$ after a ten-year follow-up. They were able to show that THA has good short- and mid-term survival in these young patients. Along with younger age within this collective, the type of bearing influenced the outcome. Thus, they reported a ten-year implant survival of $90 \%$ in patients $\geq 25$ years compared to $82 \%$ in patients $<25$ years. Ceramic-on-plastic bearings showed a ten-year implant survival of $93 \%$ versus $83 \%$ in metal-on-plastic bearings. Despite a large collective, they were not able to comment on the influence of non-inflammatory primary diagnoses on the survival rate of the prosthesis.

Few studies investigated the relevance of the primary diagnosis for implant survival in THA [18, 26, 44, 47-49]. Regarding the collective of young patients, even fewer were able to comment on DDH and implant survival [18, 47-49]. Devitt et al. and Kearns et al. both reported about higher revision rates in DDH which is in line with our findings [47, 48]. Kearns et al. reported about an odds ratio of 4.3 regarding the implant revision rate of patients with DDH compared to patients with primary OA, whereas Devitt et al. reported a significantly higher revision rate of patients with DDH compared to patients with primary OA after 20 years. Nevertheless, their collectives were somewhat older with a mean age of 42 and 41 years, respectively, and the nature of the deformity was described as mild, which makes the results difficult to compare with ours. Swarup et al. reported that THA in patients with DDH can have a good outcome [49]. But again, within their collective patients receiving a THA at an age $<25$ years are at a significantly higher risk for an implant revision with $23 \%$ compared to $10 \%$ in patients $\geq 25$ years. Hannouche et al. investigated patients who received a THA with a ceramic-on-ceramic bearing at age under 20 years and found a revision rate of $10 \%$ after ten years. In the subgroup of DDH, 2 out of 11 patients underwent a revision on the prosthetic components [18].

Our study has several limitations including the retrospective study design and the long period of inclusion with resultant heterogeneity of involved surgeons, used bearings and implants and applied surgical approaches. Additionally, there have been advancements since 1996. However, for a sufficiently large number we included all approaches and all implant types in this study.

\section{Conclusion}

This study confirms that total hip arthroplasty in patients younger than 40 years is associated with a high revision rate of $13 \%$ in 10 years. Particularly patients with developmental dysplasia of the hip are at risk for requiring revision surgery on the prosthetic components because of mechanical fatigue, with a revision rate for this indication of $17 \%$, which is significantly higher than for any other primary diagnosis (1.2\%, OR 16.8).

Acknowledgements We thank Christa Fritschi, UCAR, Balgrist University Hospital for her assistance in this research project.

Authors' Contributions SR Conceptualization, Methodology, Investigation, Writing - Original Draft. AH Conceptualization, Methodology, Investigation, Writing - Original Draft, Visualization. TT Formal analysis, Visualization. JF Investigation. PZ Resources, Supervision, Writing - Review and Editing.

Funding Open Access funding provided by Universität Zürich.

Availability of data and material The datasets used and/or analyzed during the current study are available from the corresponding author on reasonable request.

\section{Compliance with ethical standards}

Conflict of interest The authors declare that they have no competing interests or conflicts of interest.

Ethical approval The local ethical committee approved this study (Zurich Cantonal Ethics Commission, 2017-00,840).

Consent for participation and publication All patients gave their informed consent for their participation in and the publication of this study.

Open Access This article is licensed under a Creative Commons Attribution 4.0 International License, which permits use, sharing, adaptation, distribution and reproduction in any medium or format, as long as you give appropriate credit to the original author(s) and the source, provide a link to the Creative Commons licence, and indicate if changes were made. The images or other third party material in this article are included in the article's Creative Commons licence, unless indicated otherwise in a credit line to the material. If material is not included in the article's Creative Commons licence and your intended use is not permitted by statutory regulation or exceeds the permitted use, you will need to obtain permission directly from the copyright holder. To view a copy of this licence, visit http://creativecommons.org/licenses/by/4.0/.

\section{References}

1. Callaghan JJ, Forest EE, Sporer SM, Goetz DD, Johnston RC (1997) Total hip arthroplasty in the young adult. Clin Orthop Relat Res 344:257-262

2. Kinkel S, Wollmerstedt N, Kleinhans JA, Hendrich C, Heisel C (2009) Patient activity after total hip arthroplasty declines with 
advancing age. Clin Orthop Relat Res 467(8):2053-2058. https ://doi.org/10.1007/s11999-009-0756-3

3. Delasotta LA, Rangavajjula AV, Porat MD, Frank ML, Orozco FR, Ong AC (2012) What are young patients doing after hip reconstruction? J Arthroplasty 27(8):1518-25 e2. doi: https:// doi.org/10.1016/j.arth.2012.02.001.

4. Bayliss LE, Culliford D, Monk AP, Glyn-Jones S, Prieto-Alhambra D, Judge A et al (2017) The effect of patient age at intervention on risk of implant revision after total replacement of the hip or knee: a population-based cohort study. Lancet 389(10077):14241430. https://doi.org/10.1016/S0140-6736(17)30059-4

5. Kahlenberg CA, Swarup I, Krell EC, Heinz N, Figgie MP (2019) Causes of Revision in Young Patients Undergoing Total Hip Arthroplasty. J Arthroplasty 34(7):1435-1440. https://doi. org/10.1016/j.arth.2019.03.014

6. Corten K, Bourne RB, Charron KD, Au K, Rorabeck CH (2011) What works best, a cemented or cementless primary total hip arthroplasty? Minimum 17-year followup of a randomized controlled trial. Clin Orthop Relat Res 469(1):209-217. https://doi. org/10.1007/s11999-010-1459-5

7. Corten K, Bourne RB, Charron KD, Au K, Rorabeck CH (2011) Comparison of total hip arthroplasty performed with and without cement: a randomized trial. A concise follow-up, at twenty years, of previous reports. J Bone Joint Surg Am 93(14):1335-8. doi: https://doi.org/10.2106/JBJS.J.00448.

8. Mall NA, Nunley RM, Zhu JJ, Maloney WJ, Barrack RL, Clohisy JC (2011) The incidence of acetabular osteolysis in young patients with conventional versus highly crosslinked polyethylene. Clin Orthop Relat Res 469(2):372-381. https://doi.org/10.1007/s1199 9-010-1518-y

9. Wangen H, Lereim P, Holm I, Gunderson R, Reikeras O (2008) Hip arthroplasty in patients younger than 30 years: excellent ten to 16-year follow-up results with a HA-coated stem. Int Orthop 32(2):203-208. https://doi.org/10.1007/s00264-006-0309-2

10. Nizard R, Pourreyron D, Raould A, Hannouche D, Sedel L (2008) Alumina-on-alumina hip arthroplasty in patients younger than 30 years old. Clin Orthop Relat Res 466(2):317-323. https://doi. org/10.1007/s11999-007-0068-4

11. Restrepo C, Lettich T, Roberts N, Parvizi J, Hozack WJ (2008) Uncemented total hip arthroplasty in patients less than twentyyears. Acta Orthop Belg 74(5):615-622

12. Clohisy JC, Oryhon JM, Seyler TM, Wells CW, Liu SS, Callaghan JJ et al (2010) Function and fixation of total hip arthroplasty in patients 25 years of age or younger. Clin Orthop Relat Res 468(12):3207-3213. https://doi.org/10.1007/s11999-010-1468-4

13. Girard J, Bocquet D, Autissier G, Fouilleron N, Fron D, Migaud $\mathrm{H}$ (2010) Metal-on-metal hip arthroplasty in patients thirty years of age or younger. J Bone Joint Surg Am 92(14):2419-2426. https ://doi.org/10.2106/JBJS.I.01644

14. Costa CR, Johnson AJ, Mont MA (2012) Use of cementless, tapered femoral stems in patients who have a mean age of 20 years. J Arthroplasty 27(4):497-502. https://doi.org/10.1016/j. arth.2011.07.005

15. Kamath AF, Sheth NP, Hosalkar HH, Babatunde OM, Lee GC, Nelson CL (2012) Modern total hip arthroplasty in patients younger than 21 years. J Arthroplasty 27(3):402-408. https://doi. org/10.1016/j.arth.2011.04.042

16. Gililland JM, Anderson LA, Erickson J, Pelt CE, Peters CL (2013) Mean 5-year clinical and radiographic outcomes of cementless total hip arthroplasty in patients under the age of 30. Biomed Res Int 2013:649506. https://doi.org/10.1155/2013/649506

17. Garvin KL, White TC, Dusad A, Hartman CW, Martell J (2015) Low wear rates seen in THAs with highly crosslinked polyethylene at 9 to 14 years in patients younger than age 50 years. Clin
Orthop Relat Res 473(12):3829-3835. https://doi.org/10.1007/ s11999-015-4422-7

18. Hannouche D, Devriese F, Delambre J, Zadegan F, Tourabaly I, Sedel L et al (2016) Ceramic-on-ceramic THA implants in patients younger than 20 years. Clin Orthop Relat Res 474(2):520-527. https://doi.org/10.1007/s11999-015-4546-9

19. Sonohata M, Kitajima M, Kawano S, Mawatari M (2017) Wear of XLPE liner against zirconium heads in cementless total hip arthroplasty for patients under 40 years of age. Hip Int 27(6):532-536. https://doi.org/10.5301/hipint.5000513

20. Kargin D, Incesoy MA, Onac O, Albayrak A, Kaygusuz MA, Bayhan IA (2018) The effect of previous hip surgery on the outcome of hip arthroplasty in young patients. J Arthroplasty 33(9):2890 2892. https://doi.org/10.1016/j.arth.2018.04.005

21. Swarup I, Lee YY, Chiu YF, Sutherland R, Shields M, Figgie MP (2018) Implant survival and patient-reported outcomes after total hip arthroplasty in young patients. J Arthroplasty 33(9):28932898. https://doi.org/10.1016/j.arth.2018.04.016

22. Almeida F, Pino L, Silvestre A, Gomar F (2010) Mid- to longterm outcome of cementless total hip arthroplasty in younger patients. J Orthop Surg (Hong Kong) 18(2):172-178. https://doi. org/10.1177/230949901001800208

23. Chougle A, Hemmady M, Hodgkinson J (2006) Long-term survival of the acetabular component after total hip arthroplasty with cement in patients with developmental dysplasia of the hip. JBJS 88(1):71-79

24. Fourneau I (2000) Host factors that affect outcome of total hip arthroplasty. The Lancet 355(9214):1479-.

25. Girard J, Glorion C, Bonnomet F, Fron D, Migaud H (2011) Risk factors for revision of hip arthroplasties in patients younger than 30 years. Clin Orthop Relat Res 469(4):1141-1147. https://doi. org/10.1007/s11999-010-1669-x

26. Röder C, Bach B, Berry DJ, Eggli S, Langenhahn R, Busato A (2010) Obesity, age, sex, diagnosis, and fixation mode differently affect early cup failure in total hip arthroplasty: a matched casecontrol study of 4420 patients. JBJS 92(10):1954-1963

27. Röder C, Staub LP, Eggli S, Dietrich D, Busato A, Müller U (2007) Influence of preoperative functional status on outcome after total hip arthroplasty. JBJS 89(1):11-17

28. Sochart DH, Porter ML (1998) Long-term results of cemented Charnley low-friction arthroplasty in patients aged less than 30 years. J Arthroplasty 13(2):123-131. https://doi.org/10.1016/ s0883-5403(98)90089-4

29. Torchia ME, Klassen RA, Bianco AJ (1996) Total hip arthroplasty with cement in patients less than twenty years old. Long-term results. J Bone Joint Surg Am 78(7):995-1003. doi: https://doi. org/10.2106/00004623-199607000-00003.

30. Haber D, Goodman SB (1998) Total hip arthroplasty in juvenile chronic arthritis: a consecutive series. J Arthroplasty 13(3):259_ 265. https://doi.org/10.1016/s0883-5403(98)90170-x

31. Kitsoulis PB, Stafilas KS, Siamopoulou A, Soucacos PN, Xenakis TA (2006) Total hip arthroplasty in children with juvenile chronic arthritis: long-term results. J Pediatr Orthop 26(1):8-12. https:// doi.org/10.1097/01.bpo.0000187997.84213.d9

32. Odent T, Journeau P, Prieur AM, Touzet P, Pouliquen JC, Glorion $\mathrm{C}$ (2005) Cementless hip arthroplasty in juvenile idiopathic arthritis. J Pediatr Orthop 25(4):465-470. https://doi.org/10.1097/01. bpo.0000161096.53963.0e

33. George J, Miller EM, Higuera CA, Kuivila TE, Mont MA, Goodwin RC (2018) Influence of prior hip salvage surgery on outcomes after total hip arthroplasty in young patients. J Arthroplasty 33(4):1108-1112. https://doi.org/10.1016/j.arth.2017.11.008

34. Bellamy N, Buchanan WW, Goldsmith CH, Campbell J, Stitt LW (1988) Validation study of WOMAC: a health status instrument for measuring clinically important patient relevant outcomes to 
antirheumatic drug therapy in patients with osteoarthritis of the hip or knee. J Rheumatol

35. Harris WH (1969) Traumatic arthritis of the hip after dislocation and acetabular fractures: treatment by mold arthroplasty. J Bone Joint Surg Am

36. DeLee JG, Charnley J (1976) Radiological demarcation of cemented sockets in total hip replacement. Clin Orthop Relat Res 121:20-32

37. Gruen TA, McNeice GM, Amstutz HC (1988) "Modes of failure" of cemented stem-type femoral components: a radiographic analysis of loosening. Clin Orthop Relat Res 141:17-27

38. Engh CA, Bobyn JD (1988) The influence of stem size and extent of porous coating on femoral bone resorption after primary cementless hip arthroplasty. Clin Orthop Relat Res 231:7-28

39. Engh CA, Massin P, Suthers KE (1990) Roentgenographic assessment of the biologic fixation of porous-surfaced femoral components. Clin Orthop Relat Res 257:107-128

40. Syed F, Hussein A, Katam K, Saunders P, Young SK, Faisal M (2018) Risk of subsidence and peri-prosthetic fractures using collared hydroxyapatite-coated stem for hip arthroplasty in the elderly. Hip Int 28(6):663-667. https://doi.org/10.1177/11207 00017754085

41. Engh CA, Bobyn JD, Glassman AH (1987) Porous-coated hip replacement. The factors governing bone ingrowth, stress shielding, and clinical results. J Bone Joint Surg Br 69(1):45-55.

42. Brooker AF, Bowerman JW, Robinson RA, Riley LH, Jr (1973) Ectopic ossification following total hip replacement. Incidence and a method of classification. J Bone Joint Surg Am 55(8):1629-32.

43. Sanchez-Sotelo J, Berry DJ, Trousdale RT, Cabanela ME (2002) Surgical treatment of developmental dysplasia of the hip in adults: II. Arthroplasty options. J Am Acad Orthop Surg 10(5):334-44. doi: https://doi.org/10.5435/00124635-200209000-00005.
44. Seo LJ, Gabor J, Novikov D, Feng JE, Schwarzkopf R, Vigdorchik JM (2019) Outcomes in 385 developmental dysplastic hips requiring total hip arthroplasty. Arch Orthop Trauma Surg 139(5):723728. https://doi.org/10.1007/s00402-019-03143-5

45. Verra W, Kernkamp W, Van Hilten J, van de Watering L, Chander B, Bloem R (2016) Patient satisfaction and quality of life at least 10 years after total hip or knee arthroplasty. Int J Orthop 2(2):05

46. Wylde V, Blom AW, Whitehouse SL, Taylor AH, Pattison GT, Bannister GC (2009) Patient-reported outcomes after total hip and knee arthroplasty: comparison of midterm results. J Arthroplasty 24(2):210-216. https://doi.org/10.1016/j.arth.2007.12.001

47. Devitt A, OSullivan T, Quinlan W, (1997) 16- to 25-year followup study of cemented arthroplasty of the hip in patients aged 50 years or younger. J Arthroplasty 12(5):479-489. https://doi. org/10.1016/S0883-5403(97)90169-8

48. Kearns SR, Jamal B, Rorabeck CH, Bourne RB (2006) Factors affecting survival of uncemented total hip arthroplasty in patients 50 years or younger. Clin Orthop Relat R 453:103-109. https:// doi.org/10.1097/01.blo.0000238868.22852.dd

49. Swarup I, Marshall AC, Lee YY, Figgie MP (2016) Implant survival and patient-reported outcomes after total hip arthroplasty in young patients with developmental dysplasia of the hip. Hip Int 26(4):367-373. https://doi.org/10.5301/hipint.5000354

Publisher's Note Springer Nature remains neutral with regard to jurisdictional claims in published maps and institutional affiliations. 